\title{
Cambios en la economía mundial y desafios para El Salvador
}

\author{
A. Umaña
}

\section{Introducción}

En los últimos años en la economia mundial se han venido desarrollando cambios económicos de singular importancia, a los cuales no se les ha prestado la debida atención, específicamente en el significado que estos tienen y tendrán para la economia salvadorena. Para ciertos analistas estos cambios son percibidos como desajustes estructurales, otros los encierran gruesamente como la frase lapidaria de "Crisis del sistema económico mundial".

La problemática inmediata, la guerra y la situación económica, hacen que aquellos problemas estratégicos sean percibidos como distantes o secundarios.

En el fondo de estas percepciones, aunque, no reconocidas explicitamente, se encuentran cualquiera de las siguientes ideas:

- El reloj de la economia mundial está detenido para el país, esta es una situación estática de crisis. Básicamente es lo mismo la busqueda de una reinserción en el escenario mundial ahora que dentro de diez años. En este sentido, lo que cuenta es que nos concentremos exclusivamente en resolver la crisis de la sociedad salvadoreña. Lo interno es lo fundamental y lo externo, o sea, la relación con la economia mundial, va a depender de la configuración estructural de la economia salvadoreña (lo interno).

- La crisis económica salvadoreña se percibe como una baja de la producción y desajustes macroeconómicos. Una vez estos sean superados, El Salvador entrará en una ruta de normalidad en su crecimiento y relaciones económicas con el mundo. Interesará seguir el 
ejemplo del sureste asiático integrando al país, por ejemplo, al estilo Singapur. Si esto fue posible para ese país en las pasadas decadas, en el futuro está abierta esta posibilidad para El Salvador.

- Las estructuras económicas una vez sean cambiadas permitirá una inserción autónoma de nuestra economía en el escenario mundial. La estrategia central es la autosuficiencia basada en una estrategia de seguridad alimentaria. Los cambios tecnológicos y la crisis en las relaciones son en estas perspectivas, un problema de las multnacionales y de los paises perifericos capitalistas.

Junto a estas perspectivas teóricas' se dan marcos metodológicos de interpretación sobre la relación de lo nacional con lo internacional. Por un lado conciben la economia nacional como determinada o dependiente de la internacional. Por otro lado, en una aplicación mecanicista de la dialéctica de lo externo con lo interno, se identifica lo nacional como 10 interno y fundamental y lo externo, lo internacional, como factor condicionante pero no determinante.

Sin desconocer la importancia inmediata del conflicto "interno", a la vez es necesario poner atención en los importantes fenómenos económicos mundiales que tendrán a corto y largo plazo una significación muy específica para nuestra economia, más alla de la salida que encuentre el conflicto salvadoreño. Está situación se ve reforzada por to que se llama el intersticio entre períodos mundiales, aunque esto no esta muy bien definido, se identifica un momento de transición 1985-1995. Interface que implicará retrocesos en las relaciones de intercambio y de especialización apra cientos paises que se encuentren a la saga de las tendencias mundiales. Más concretamente, no se trata de un reordenamiento sólo de los paises capitalistas centrales o de la jerarquía económica entre esto y el tercer mundo. La particular configuración económica mundial inciada en la segunda postguerra esta llegando a su fin, los cambios en proceso, están implicando una nueva estructura económica mundial que va más alla de un reordenamiento internacional.

El Salvador tiene muy poca o casi nula insidencia sobre la orientación de estos fenómenos y las perspectivas no son alagueñas para los países del tercer mundo como el nuestro, razón de más para no permanecer pasivo ante estas tendencias y buscar alternativas estrategicas que coloquen al país, al menos en una situación que no lo desmejore en la ubicación estructural.

Estos fenómenos están mucho más alla de aparecer en las relaciones econométricas o en la evolución de los grandes agregados económicos internacionales, tales como los balances comerciales, los tipos 
de cambios o las relaciones de intercambio. Los desajustes de estos agregados, más bien manifiestan el final de una época para la cual expresaban, como cantidad, adecuadamente la calidad de las relaciones internacionales en las cuales se basaban. Más aun la crisis en la economia mundial tiene como base cambios profundos a su interior que pugnan con esquema de relaciones intemacionales que se presentan ante estos nuevos cambios como restrictivos y constritivos. Reducir el problema actual de la economía mundial aun problema de desajustes en las balanzas de pagos, a la deuda externa, los déficit fiscales, el deterioro de los términos de intercambio, etc. Es simplemente apreciar la punta de unh lceberg.

La discusión sobre la problemática y las tendencias implicitas hasta hace unos pocos años estaba circunscrita a grupos demaciados especializados pero de hace unos cinco años a la fecha se ha desarrollado una intensa discusión y labor investigativa al respecto. Los esfuerzos en investigaciones y publicaciones realizados por el Grupo de Roma, PROMETHE, ESPRIT, RACE, EUREKA, etc. sobre este tema es abundante. En América Latina para no ir muy lejos existen publicaciones y se han realizado a la fecha un número de eventos al respecto. Por ejemplo, el Seminario organizado por el INTAL y la CEPAL en homenaje al Dr. Raul Prebisch, tenia como centro de discusión esta problemática "América Latina en la economia mundial".

Tomando en cuenta lo anterior, las preguntas que se plantean como problema son:

- ¿Cuales son los cambios en las relaciones técnicas y económicas que se están desarrollando en la economía mundial y cómo estas afectarán a nuestro país?

- ¿Cuales son las tendencias y las caracteristicas más sobresalientes 0 más definidas a la fecha en esa nueva estructura mundial, y que perspectivas se le presentan a El Salvador en el llamado periodo de transición?

- ¿Cuales podrian ser las tareas estratégicas para el pais en este contexto internacional, y en el contexto específico de la guerra por la cual se atravieza?

\section{Fenomenología de la crisis económica internacional}

Cuando se habla de la actual crisis del sistema económico internacional se hace referencia usualmente, en cuanto a tiempo, a un periodo que va de inicios de la década de 1970 hasta la década de 1980. 
Los síntomas de la actual crisis se manifiestan a finales de la década de los sesenta pero ésta se inicia claramente a partir de la recesión de 1973. Con ciertas excepciones como Japón, en todas las economias industrializadas se reducen las tasas de crecimiento (PIB) o adoptan signos negativos, la inversión bruta, bajan los volumenes de comercio internacional, se abandona el sistema monetario internacional basado en el dólar como dinero mundial que anteriormente había sustituido al oro, se incrementan las tasas de desempleo y de inflación, y aparece un nuevo fenómeno conocido como Stagflación que desconcierta a los economistas keynesianos, etc.

Inicialmente esta situación se manifiesta en los paises centrales pero luego en todo el mundo, desarrollandose otros fenómenos económicos: deterioro en los términos de intercambio norte-sur, alzas en las tasas de interés, déficit en las balanzas de pagos, resurgimiento del proteccionismo, aumento de la pobreza en términos absolutos y relativos, golpes de estados y entronización de regímenes militares, guerras, etc. Existen periodos breves de recuperación para caer de nuevo en tasas bajas de crecimiento o en el estancamiento. En 1982 estalla la crisis de la deuda externa para el tercer mundo, especialmente para América Latina.

En 1983 la economía norteamericana mostraba haber iniciado un proceso de ascenso, llegando en 1984 a una de las tasas mayores de crecimiento del producto nacional bruto desde la segunda guerra mundial $(6.6 \%)$, se reducia la inflación, el desempleo y las tasas de interés, las tasas de cambios habian reducido sus grandes oscilaciones y se mostraban básicamente estables.

Se habla de una nueva etapa "La era de Reagan" y EU aparecia como la locomotora que arrastraría a todas las economías industrializadas en una franca recuperación económica y posteriormente a los restantes paises subdesarrollados, aunque en estos en un principio no se evidenciara la recuperación.

En la reunión de septiembre de 1987 de los Ministros de Hacienda y Gobernadores de los Bancos Centrales de las siete principales potencias económicas, éstos manifestaban satisfacción con las tasas de cambio y la recuperación económica experimentada en los últimos años.

Por otro lado los grandes cambios tecnológicos en materia de informática, biotécnica, quimiotécnica, etc., despertaban grandes expectativas con respecto a una nueva base técnica de la economía y se preveia una recuperación acelerada de los indices de productividad.

La luz del tunel se veía por fin, cuando ante indicios de una nueva alza en las tasas de interes, sobreviene el Crack de la Bolsa de Valores 
de Nueva York en el último trimestre de 1987. Lo fragil de la recuperación económica se evidenciaba. A la par de ésta, se habian desarrollado grandes desequilibrios comerciales y financieros. El Director Gerente del Fondo Monetario, poco antes del crack económico había advertido que la situación sería insostenible más allá de 1988 si no se introducian programas de ajuste ante los déficit fiscales, financieros y comerciales de EU principalmente con Alemania y Japón. Se habla de la próxima recesión económica esperada para 1989-90 y se empieza a especular sobre su magnitud, duración y significado para la economia internacional.

En el otro lado de la economía mundial, después de que el Partido Comunista venía sosteniendo lo contrario, Gorbachev reconoce un periodo de estancamiento y hasta de deterioro de la economia soviética en la década de los setenta y anuncia profundos cambios en política económica interna, en las relaciones con el mercado internacional y acorde con ellos, en el sistema político (Perestroika y Glasnost).

Plantea una reconversión técnico científica en la planta industrial y en toda la sociedad y una mayor integración a la economia mundial por medio de su incorporación paulatina al GATT. China, Polonia y Rumania han abierto sus economias a la inversión de capital externo y en diferente grado han introducido modificaciones a sus sistemas políticos. Los últimos incidentes tanto en China como con las elecciones en Polonia muestran dos formas diferentes de encarar los desafíos políticos ante los cambios económicos en marcha.

El panorama mundial parece confuso y contradictorio. Por un lado existen indicios de una nueva era económica, pero por el otro, pareceria que la economia tiene un futuro de desequilibrios y estancamiento o de raquítimo crecimiento.

Mucho más aca, en C.A. y más específicamente en El Salvador, aquellos acontecimientos parecen muy distantes a pesar que la crisis económica mundial se manifiesta aqui de forma mucho más aguda y concreta: la guerra, primero con el triunfo de la revolución Sandinista y luego con el desarrollo de fuertes movimientos insurgentes en Guatemala, El Salvador y en diferente grado en Honduras. Después de varios años de guerra y de preveerse un próximo desenlace, a la fecha el panorama parece de estancamiento. El triunfo de ARENA y las recientes propuestas del FMLN, dependiendo del punto de vista, pueden significar situaciones prospectivas muy diferentes.

Todos estos acontecimientos se presentan desvinculados unos de otros como una voragine que llenan nuestra atención e imposibilitan el establecimiento de relaciones entre ellos. Muy frecuentemente los análi- 
sis no sobrepasan este nivel del aparecer de las cosas, sin embargo, para tener una visión aproximada que supere lo fenoménico, es preciso vincular los acontecimientos cotidianos y cercanos de nuestra realidad a aquellos que parecen distantes e irrelevantes.

Para un entendimiento de las perspectivas económicas salvadoreñas es necesario establecer una concepción de la crisis actual en su vinculación con la crisis mundial y contextualizarla en el marco histórico en que se han desarrollado.

\section{Dinámica y cinemática de la crisis}

Las crisis económicas, tanto nacional como internacional, no son momentos anormales, más bien son fases en el proceso de desarrollo que separan estados cualitativos o configuraciones específicas de las cosas o seres.

Las crisis en si mismas no son malas ni buenas, más bien, desde un punto de vista científico, son etapas necesarias en las cuales se agudizan las contradicciones inherentes creando condiciones para su resolución (o regresión), sentando la base de nuevos estados del desarrollo. Las crisis son momentos decisivos por medio de las cuales se desarrollan cualitativamente las cosas, sin crisis no hay desarrollo.

En las crisis socioeconómicas entran en desintegración las relaciones (estructura) que sentaban la base o caracterizaban la especificidad de un periodo de la sociedad.

La superación progresiva de la crisis implica la articulación de nuevas configuraciones en las relaciones que permitan un espacio más amplio de desarrollo. Lo contrario, salir de la crisis sin superarla, implica entrar a estados regresivos, de estancamiento o de crisis futuras recurrentes. En la economía mundial visto como un todo se pueden identificar históricamente dos tipos y niveles de crisis.

a. Las crisis Cíclicas como fases de la rotación (reproducción) del capital y la sobreproducción periódica como producto de las transformaciones cuantitativas en la composición interna (orgánica) del capital.

b. Las crisis Seculares que implican cambios cualitativos en las relaciones económicas, específicamente en la composición de valor y la composición técnica de la economía en su conjunto. Son cambios cualitativos en las relaciones de producción manteniendo invariante su especificidad como tal.

La actual crisis internacional (70's-80's) expresa la desarticulación de 
un bloque histórico mundial que se configura de una forma clara, a partir de la segunda guerra mundial. Su surgimiento se puede ubicar en los acuerdos de Breton Wood y de Yalta que ordenan el sistema económico en dos bloques, crean un sistema monetario basado en el dólar (FMI), permiten una nueva articulación productiva y comercial por medio del GATT y el desarrollo de las transnacionales; crean un sistema financiero mundial (por medio del BIRF y el FMI) y el surgimiento de un nuevo sistema de naciones por medio del proceso de descolonización y el surgimiento de las NNUU.

Todo este sistema comprendido como un todo, ha entrado en crisis en sus diferentes componentes y bajo diferentes formas. Por ejemplo, la deuda externa de AL entendida desde esta perspectiva, es una manifestación de la crisis del sistema financiero como parte integrante $y$ expresión de la crisis económica mundial.

Este orden mundial tiene como base de surgimiento una crisis y como punto de terminación otra. Si nos detenemos a analizar la historia del desarrollo del sistema económico capitalista, se pueden contextualizar estas grandes crisis seculares que expresan el fin y a la vez el surgimiento de grandes períodos de existencia de bloques históricos mundiales del capitalismo.

Estas crisis seculares no son las crisis cíclicas de las rotaciones del capital social, son crisis estructurales, crisis de configuraciones. Estos bloques históricos se desarrollan por medio de las crísis cíclicas pero perecen y se transforman en nuevos bloques por medio de crisis seculares.

Históricamente se pueden ubicar cuatro grandes periodos del capitalismo y por lo tanto, cuatro grandes configuraciones y crisis seculares:

- El primer período abarca desde la revolución industrial hasta 1852.

En 1847 se inicia la primera gran crisis industrial en Inglaterra y las grandes conmociones sociales en Europa que fueron superadas más o menos en 1852. En ese entonces el centro del sistema de las economías industrializadas se reducia a Gran Bretaña, Bélgica y Holanda. La "periferia inmediata y supeditada" eran los demás paises europeos donde las contradicciones estallaron como revoluciones sociales. Alemania por ejemplo, en ese entonces era un pais eminentemente agrícola $y$ atrasado. 
- El segundo período a partir de 1852 hasta 1890.

En 1852 luego de la creación de un nuevo espacio económico en Europa, se entra a un proceso de rápida expansión económica y consolidación de un nuevo bloque $\left(2^{9}\right)$ basado en nuevos procesos técnicos y en un nuevo orden inter-naciones. A inicios de la década de 1870 de nuevo sobreviene otra gran crisis secular que dura hasta más o menos 1890 .

\section{- El tercer perlodo a partir de 1890 hasta 1945.}

De la segunda crisis surge un nuevo orden económico internacional $\left(3^{9}\right)$ caracterizado por lo que se denominó el imperialismo formal, colonialismo, era de los monopolios. También se desarrolla una nueva base técnica, surgen los diferentes tipos de motores de combustión interna, la revolución de las comunicaciones, etc.

La primera guerra mundial expresa el límite de su expansión y el inicio de la tercera gran crisis secular. Los límites y contradicciones del desarrollo del sistema no son resueltos por dicha guerra así, la primera post-guerra es un periodo de espera, de paz armada, de crisis recurrentes y más profundas (1929), de desempleo, inflación, etc.

Fue hasta la segunda guerra mundial cuando definitivamente encuentran su resolución y se inicia el proceso de desarrollo del actual bloque histórico mundial. La primera y segunda guerra mundial son históricamente, una sola guerra desarrollada en dos etapas cuya finalidad histórica era superar los límites en la configuración de las relaciones internacionales. El sistema de naciones y monopolios constrefian el desarrollo de las fuerzas productivas a nivel mundial.

\section{- El cuarto período a partir de 1945 a la fecha.}

De esta tercera crisis surge el actual sistema económico $\left(4^{2}\right)$ y en, las transnacionales como la nueva forma de articulación productiva a nivel mundial. El desarrollo de la nueva base técnica (electrónica, la primera generación de computadoras, la energía atómica, industria aeroespacial, motores de reacción, etc.) habria sido imposible en el anterior sistema de monopolios e imperios caracterizado por barreras comerciales y proteccionismo. Se necesitaba un espacio económico mucho más amplio, una nueva naturaleza de naciones y de relaciones internacionales.

Cada uno de éstos periodos se caracteriza de forma histórica por tener como base y como terminación la desarticulación de una estructura de relaciones por medio de una crisis, una nueva base técnica (entendida como proceso y relaciones en la división entre ramas y naciones 
del proceso productivo), un particular significado del estado-nación, un sistema internacional y también una estructura comercial, financiera, etc., diferente.

Cada nuevo periodo ha significado una expansión gigantesca de las fuerzas productivas en comparación con el anterior. Las magnitudes de valor entre un período y otro son inmensurables en una misma escala y han implicado en cada crisis, lo que se denomina revoluciones en las relaciones de valor. De forma gráfica los períodos y crisis se pueden representar de la siguiente forma:

Cada periodo.

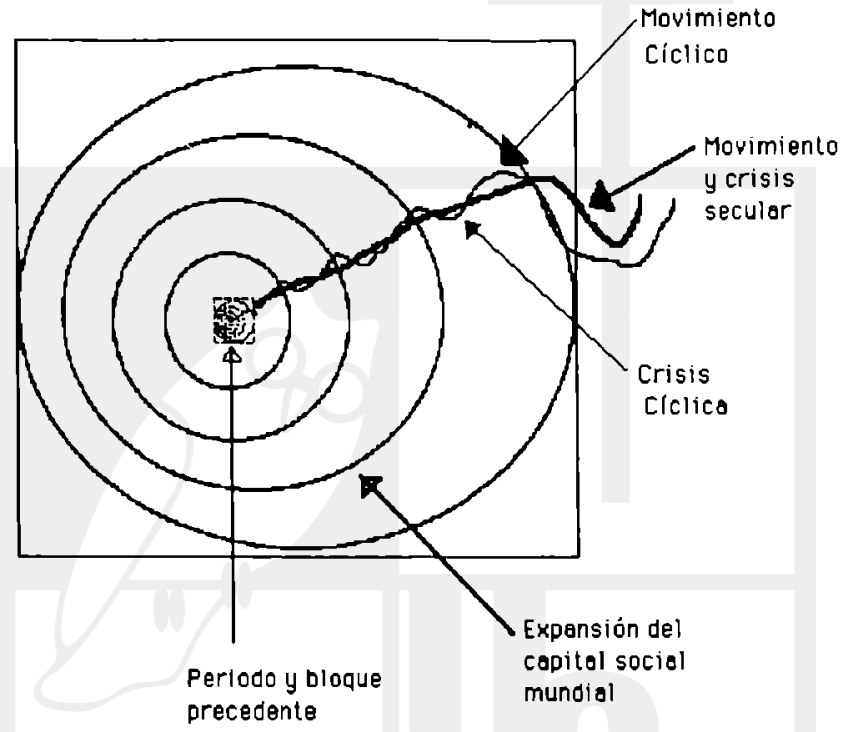

Cada nueva crisis secular ha involucrado un mayor espacio social y económico que la anterior y modificado el panorama económico mundial, precisamente porque cada nuevo periodo ha comprendido y subordinado a un mayor número de países dentro de su eslera. El grado en que éstas crisis afectan o son registradas en la historia económica de cada país, esta determinado por el momento y tipo de vinculación con el mercado mundial. En cada periodo es diferente la naturaleza del estado-nación y su inserción en la economia mundial. Decaen ramas industriales enteras y surgen otras nuevas o se readecuan su preminencia dentro de la estructura técnica del capital social mundial. La magnitud de la crisis en 


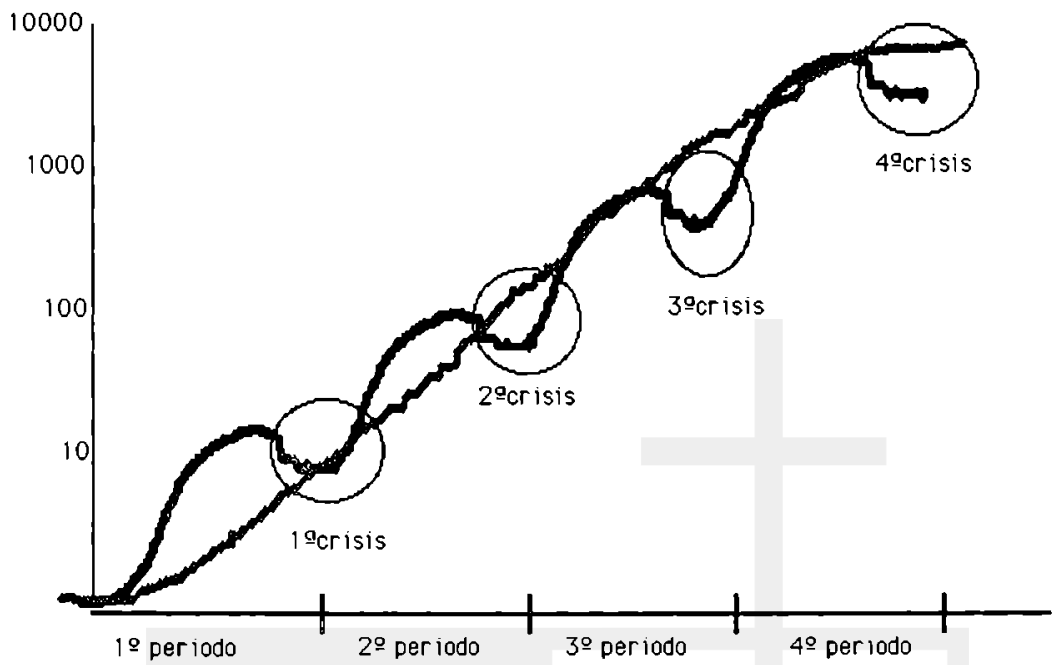

el desmoronamiento de ramas enteras es muchas veces oscurecida por el acelerado crecimiento de las nuevas ramas económicas y los cambios en las relaciones de valor.

\section{Las crisis en EI Salvador.}

Estos grandes movimientos seculares se pueden identificar en nuestro país por medio de variables adecuadas que de forma próxima expresen la evolución de la economía salvadoreña y la articulación dentro de la economía capitalista mundial.

En nuestro caso, la exportación del añil, luego del café y por último la evolución del PIB, sirven para identificar estos movimientos:

Para el primer período (1780-1847), no se dispone de registros económicos o datos sobre las exportaciones salvadoreñas ya que éstas se empiezan a registrar y sistematizar a mediados de la década de 1860 , tanto para el añil como para el café. Para los últimos tres periodos es posible identificar las crisis salvadorenas como parte de las crisis mundiales, tal como se puede apreciar en el siguiente conjunto de gráficos: 


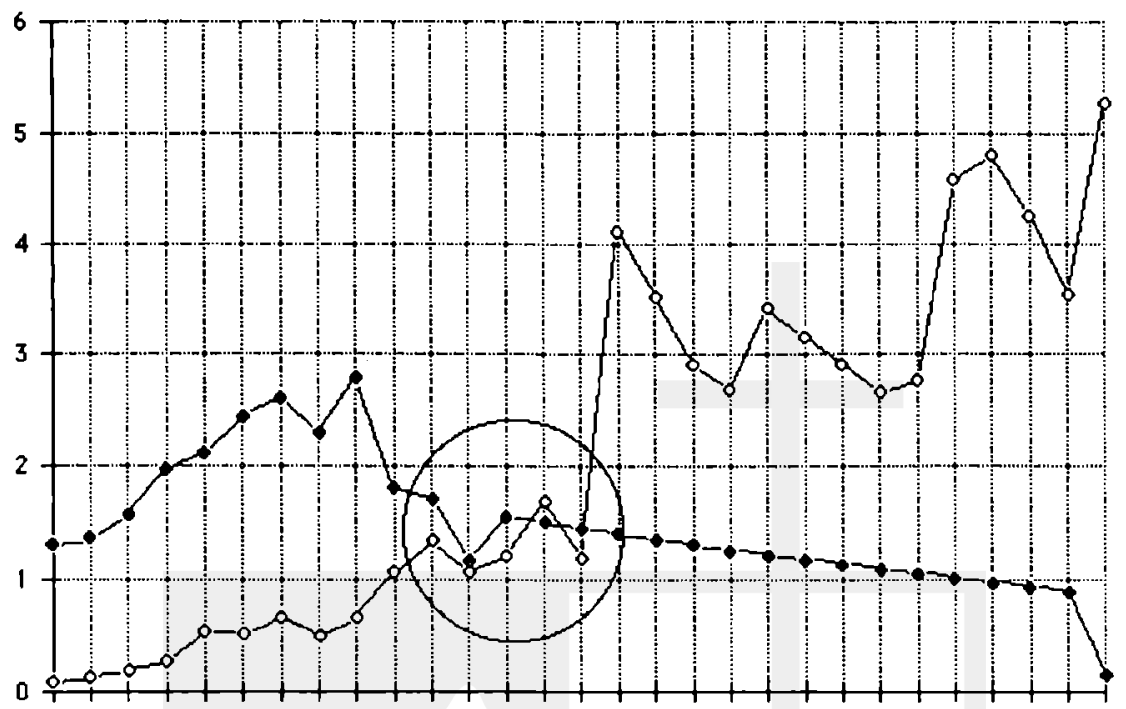

186465666768697071727374757677787980818283848586878889909192

\section{ANIL O- CAFE}

La crisis del añil producida por las transformaciones técnicas y de la composición orgánica del capital en la industria textil tuvo efectos evidentes en la economia salvadoreña. La decadencia de amplias zonas geográficas añileras (norte y paracentral del país) y la transformación y sustitución cualitativa por la producción del café es muy clara en los datos sobre las exportaciones de ambos productos en la segunda mitad del siglo pasado.

Esta crisis representó cambios en la estructura económica salvadoreña, en el espacio geoeconómico, en los tipos de productos, en las ramas, etc. Las expropiaciones modificaron las relaciones de propiedad en el principal medio de producción, la tierra. Han sido poco estudiadas las conmociones sociales, sublevaciones etc, que se dieron en esos años, la relevancia histórica de esta crisis y todos sus acontecimientos fueron opacados por la siguiente crisis que tiene su punto culminante en los acontecimientos de 1932. 


\section{Exportaclones de café}

(millones de pesos)

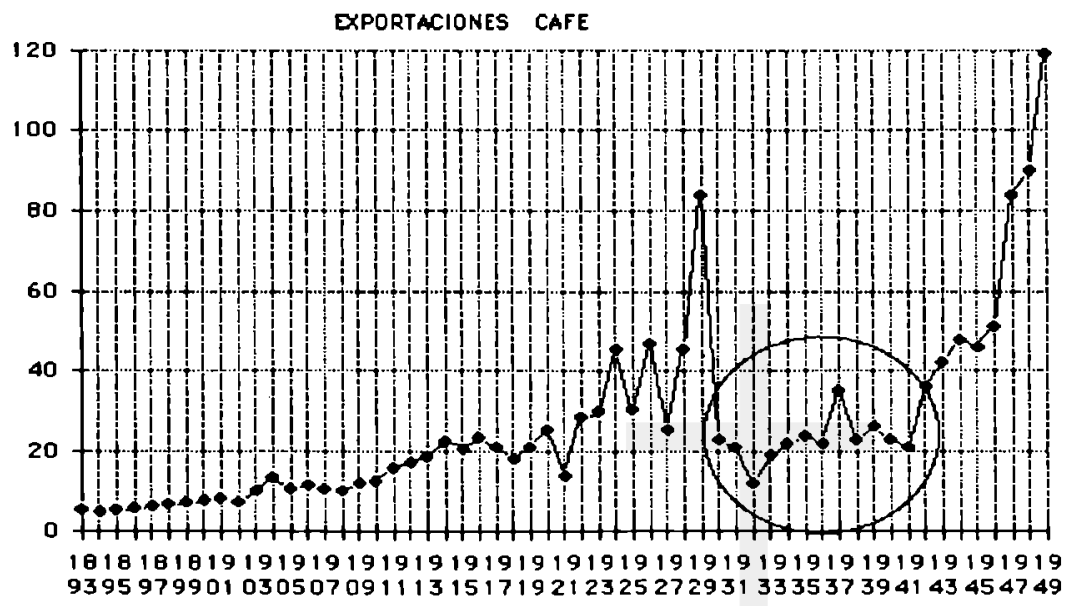

Para el caso de El Salvador la actual crisis expresa el final de un período económico que tiene su origen en el derrocamiento del General Hernández Martínez en 1944 y la revolución de los Mayores de 1948.

$\mathrm{Si}$ bien es cierto que hay una continuidad de regimenes militares, es. erroneo no identificar las diferencias en el modelo de acumulación entre un periodo y otro. El régimen de Hernández Martínez significó la reafirmación de un modelo anterior a pesar de ciertas reformas introducidas en su gobierno.

\section{PIB de EI Salvador en millones de colones basse 1962}

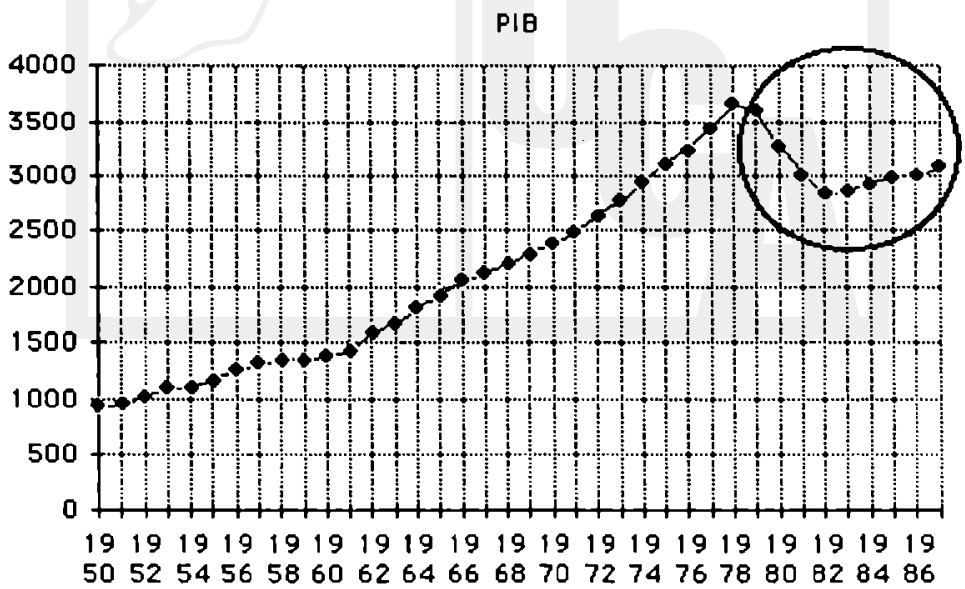


Es a partir de la Junta de los Mayores que se inicia una readecuación de la estructura económica y una nueva forma de integración con la economia mundial. Sin embargo, la forma adoptada no logra romper de forma esencial con el modelo anterior. A pesar de ésto, se puede apreciar una modernización de la infraestructura económica, la diversificación mínima del agro (por medio del algodón y la cańa de azúcar), un proceso incipiente de industrialización, una modernización del aparato de estado y de la legislación laboral, un proceso de integración económica con Centroamérica, etc.

Lo limitado de la restructuración en la base del modelo determinó el límite de su capacidad de expansión y la profundidad de crisis en la decada de los 70's y 80's sentandose asi la base objetiva para el surgimiento de diferentes organizaciones que propugnan por un cambio radical en la sociedad salvadoreña.

El rápido desenvolvimiento de los acontecimientos a partir de 1979, las reformas económicas (agraria, bancaria y del comercio exterior), del sistema político por medio de las elecciones y la forma de estado, el establecimiento de un nuevo orden jurídico básico (constitución), el desarrollo de la guerra, la restructuración de la FFAA y la próxima reforma tributaria están configurando un nuevo bloque histórico en El Salvador.

La actual crisis es claramente una transición hacia un modelo económico en configuración, es decir, aun no cimentado, cuyas perspectivas estructurales estarán claramente determinadas por la forma y el momento en que se defina el conflicto actual.

Lo que es claro es que por la actual relación de fuerzas de los grupos económicos y políticos, El Salvador no podrá regresar al pasado, y que en el presente se está debatiendo las nuevas relaciones de poder político y económico dentro del proceso de configuración de una nueva estructura hegemónica.

Seria errado buscar aisladamente las nuevas características del sistema económico que se pretende configurar en El Salvador al margen de la estructuración del modelo de acumulación a escala mundial. Es en éste panorama en el que la estructura económica salvadoreña se inserta, contexto que a la vez aun no esta definido, sino que se debate precisamente en ese proceso y en él están involucrados tanto las economias capitalistas como socialistas. Esto es válido tanto si la resolución de la guerra en nuestro país apuntara hacia un sistema de economia planificada como hacia una nueva forma de economía de mercado. En éste nuevo contexto no son posibles la edición repetida de la experiencia de 
Singapur o de Chile, de Albania o de Cuba.

Con una escala logarítmica en el eje vertical y la sobreposición de las diferentes variables, se puede obtener el siguiente gráfico que expresa el movimiento histórico del conjunto de la economía salvadorefía en los últimos cien años.

Crisis y periodos históricos de la economia salvadorefia

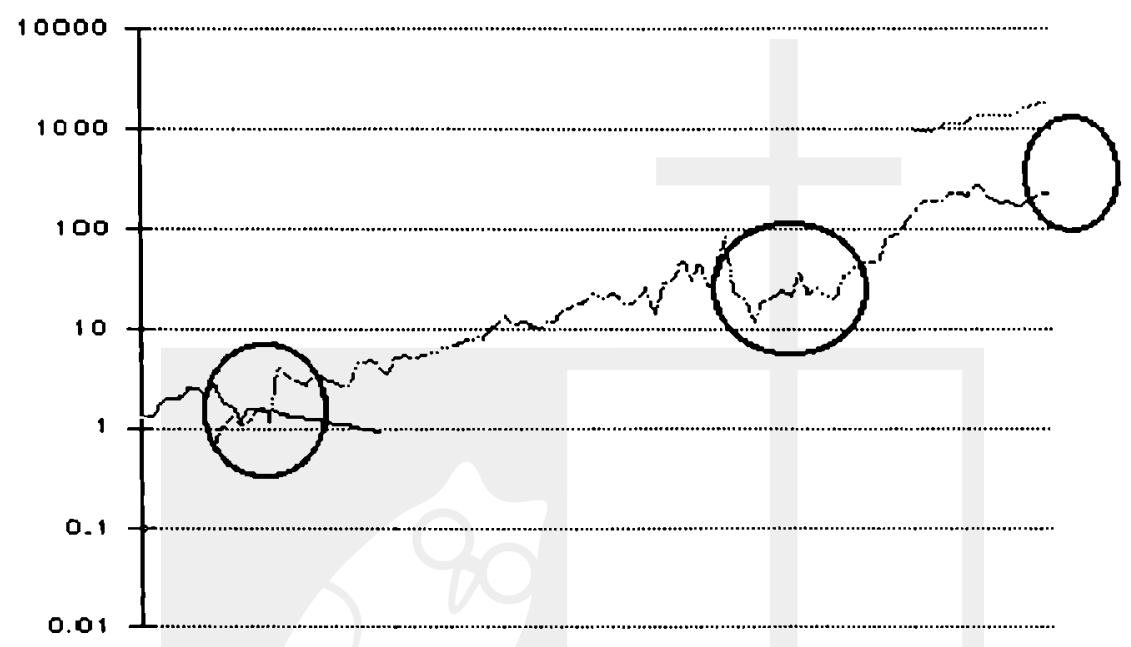

Magnificando y sobreponiendo el último período:

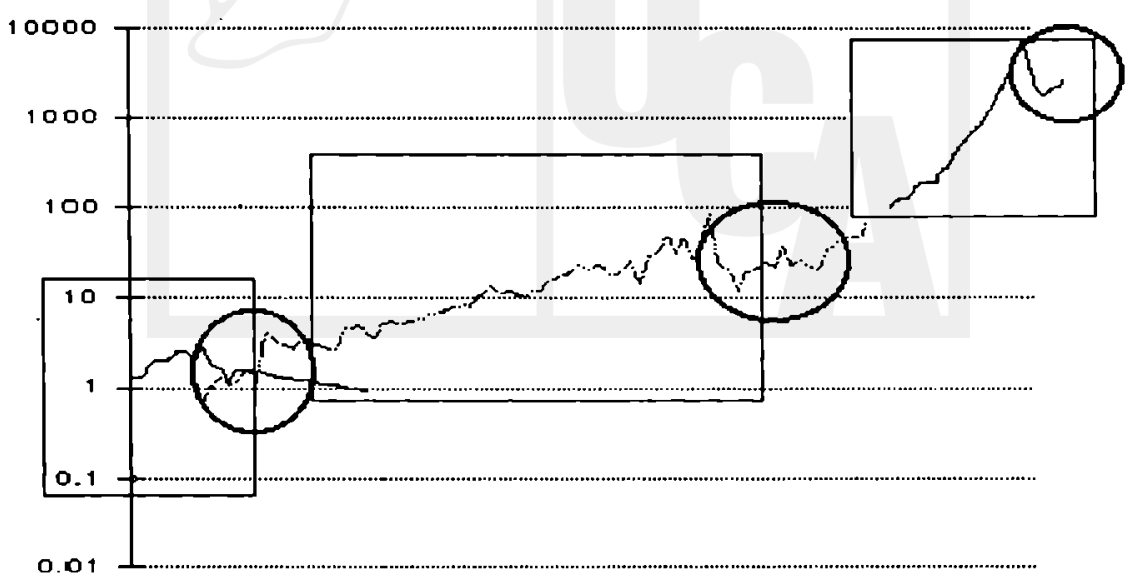




\section{Tendencias del nuevo modelo de reproducción a escala mundial}

Al igual que las anteriores, la actual crisis del sistema económico, es el producto de conmociones en la composición interna del proceso y de las relaciones de producción. Cada periodo ha surgido de profundas transformaciones cualitativas en la composición orgánica del capital que conllevan transformaciones en las relaciones de valor y en las relaciones técnicas del proceso de producción.

Las crisis sobrevienen por la imposibilidad de las relaciones económicas de dar espacio para el desenvolvimiento de la nueva base técnica desarrollada sobre la base de la anterior y en la postrimeria del periodo.

Un periodo, caracterizado por una especial configuración de relaciones, desarrolla, perfeccionando, su base técnica. Las relaciones económicas, tal cual caparazón, permite su desenvolmiento hasta el momento en el que al interior de él se va desarrollando una nueva que acelera el agotamiento de las formas económicas por medio de una crisis. Esta nueva base técnica reclama un nuevo espacio en las relaciones económicas y una nueva forma de expresarse a través de las relaciones de valor.

Las crisis seculares en ésta perspectiva, son transformaciones cualitativas, revoluciones de las relaciones de producción dentro de la invariante de la relación salarial que caracteriza al sistema productivo capitalista.

Estas transformaciones se basan en cambios en las relaciones técnicas de producción que implican cambios en el objeto de trabajo, en los instrumentos, en los procedimientos, en la división técnica entre los hombres y sus niveles de calificación, en la configuracion técnica y el peso relativo de las ramas y de los grandes sectores económicos.

La visión formalista de éstos cambios la reducen a elevaciones significativas en la productividad. Esta perspectiva no rebasa las formas económicas y no profundiza en el contenido técnico de las transformaciones.

Las transformaciones en la composición técnica del capital son un cambio en el instrumento y en los procedimientos de trabajo (que también significan cambios en la calificación de la fuerza de trabajo), que implican a la vez, nuevos objetos de trabajos ya que el instrumento antes de ser tal ha sido objeto de trabajo. Estos a la vez provocan cambios en las industrias extractivas y agropecuarias que proporcionan los materiales generales. Hay transformaciones en los pesos relativos de 
las diferentes subramas por desplazamiento entre ellas y por el surgimientos de nuevas (como ejemplo, se puede citar las perspectivas sombrias para la industria del cobre en Chile ante el desarrollo de la fibra óptica de vidrio).

Los cambios en las ramas vinculadas al proceso de elaboración de los instrumentos de trabajo determinan a la vez, cambios significativos en todas las demás ramas, tanto en las básicas ${ }^{2}$ (extractiva y agropecuaria) como en las de consumo final.

En este último sector se da el surgimiento de nuevas industrias suntuarias y desplazamientos de antiguas hacia las de consumo final, modificando estilos de vida y las relaciones de valor por transformaciones en los costos de reproducción de la fuerza de trabajo.

Nadie duda a esta altura que estamos en presencia de una completa revolución tecnológica que está cambiando la estructura técnica entre ramas. Como industrias de vanguardia y su consecuencia inmediata, se pueden identificar las siguientes:

- La industria de la informática se está revelando como de importancia estratégica a nivel económico, político, militar e ideológico. La informática se esta planteando como hilo conductor y vinculante entre todos los diferentes tipos de empresas. Esta industria de datos, no se restringe a su forma alfanumérica (letras y números) incluye datos geométricos de alto valor, tales como los disefios de productos, mapas, diagramas, etc. Los productos materiales, los sistemas de defensa, la búsqueda y explotación de nuevos yacimientos de materias primas son la sustantivación, de diferente forma, de datos geométricos, altamente cotizados en el mercado. La información se ve aqui como producto de consumo final o como insumo para la elaboración en otras industrias tanto de la misma rama como de otras, así como instrumento de dominación.

Incluye la información como objeto de trabajo y los software. Esta industria tiene una cardinal importancia en la integración económica y en la transformación del mapa geopolítico mundial.

- La electrónica en la construcción de nuevos medios de comunicación, en la manipulación del electrón, en la industria del Hardware, específicamente en el desarrollo de nuevos microprocesadores, etc. y en el desarrollo de la robótica.

- La quimiotécnica tiene su especial importancia en el desarrollo de nuevos materiales de trabajo y en la aceleración de procesos productivos con materias instrumentales. Su importancia radica en sus efectos en la producción de materias primas en el tercer mundo. Esta industria se 
caracteriza por la manipulación de sustancias para la trasformación de propiedades químicas de los objetos.

- La biotécnica que consiste en la manipulación de organismos y su utilización como instrumento de trabajo para afectar las propiedades orgánicas de otros seres vivos. Su impacto en la producción alimenticia en todas las subramas agropecuarias y en la agro-industria, tiene ya consecuencias dramáticas en la producción de carne, trigo y maiz por citar algunos ejemplos.

- La industria energética en el desarrollo de nuevas fuentes de energía.

Estas transformaciones técnicas traen en primera instancia transformación en los capitales, específicamente en su proceso y estructura administrativa, simplificandole, sintetizándole, volviéndole más ágil e integrado a tal punto que las empresas del anterior periodo aparecerán como grandes dinosaurios ante el desarrollo de un sistema nervioso altamente desarrollado por medio de la telemática. Además, cambian la nomenclatura de las transnacionales, permitiendo por un lado una mayor centralización de capital a nivel mundial y volviéndolas más incapturables en los espacios nacionales.

Dada la envergadura de las nuevas empresas se están dando procesos de entretejidos y relaciones "Matriciales" entre transnacionales y capital de estado, expresadas como coinversiones entre gobiernos y empresas de grandes magnitudes Con diferente signo, se puede identificar por ejemplo, el gaseoducto Soviético, las inversiones de multinacionales en China o Rumania, o la gran iniciativa financiera que implica la iniciativa de defensa estratégica (Guerra de las Galaxias), etc.

En otra dirección se han desarrollado formas empresariales muy particulares del nuevo periodo, que se han denominado las "Redes de Empresas" o las "Empresas Redes" que se constituyen en desafío de lo pequeño organizado y con flexibilidad de respuesta ante lo grande y desproporcionado. Se hace el parangón de esta nueva figura del capital con el significado histórico que las sociedades anónimas tuvieron en el Tercer período del capitalismo y el desarrollo de los monopolios a finales del siglo pasado. Por un lado se ven como un desafio para las grandes multinacionales pero por otro como perfectamente articulables.

Asi se identifican tres nuevas figuras históricas de empresas: una nueva forma de transnacional, una empresa matricial como producto de la asociación entre capital de estado y transnacional y por último, las empresas redes. 
La estructura técnica del proceso productivo entre grupos humanos y ramas así como la configuración administrativa de la nueva forma de empresas y sus relaciones económicas, son la base sobre la cual se constituyen los mapas de naciones. Los cambios en los dos primeros factores necesariamente empiezan a exigir un reordenamiento de las relaciones internacionales tanto económica como políticamente. No es la estructura inter-nacional la que explica las relaciones de producción, la división técnica y la relación entre ramas. Es precisamente lo contrario, si el sistema Inter-nacional ha entrado en crisis es precisamente porque este impide el desarrollo de las fuerzas productivas.

Los grandes desequilibrios entre naciones tanto financieros, como comerciales, son el resultado del agotamiento del particular sistema de naciones que surgió en la segunda guerra mundial. Aquí es precisamente importante resaltar y rescatar la categoría de totalidad para la configuración de la teoría del desarrollo.

Es imposible explicar científicamente el desarrollo económico de las naciones al márgen o de forma abstracta, desligada del desarrollo de la estructura productiva del capital social-mundial. La explicación de los diferentes momentos de las naciones, su articulación, su estructura hegemónica, su "desarrollo" o "subdesarrollo" son un nivel de la realidad que encuentra su explicación más profunda en la reproducción orgánica del capital social como totalidad mundial.

La nueva base técnica del capital exige un nuevo orden del sistema internacional, entendido no en su accepción ética o como usualmente se identifica como reivindicación del tercer mundo. Entendido más bien como un nuevo mapa geoeconómico y político adecuado a las tendencias del capital.

Al respecto se pueden identificar grandes tendencias:

- La conformación de una nueva estructura productiva tanto a nivel técnico como a nivel económico que implica cambio en el orden jerárquico de las ramas, surgimiento de nuevas, transformación o desaparecimiento de otras, relocalización en el espacio geoeconómico.

- Una transformación cualitativa en el significado y poder efectivo del Estado-nación.

La dominación espacial que éste implica se verá fuertemente modificada por las transformaciones técnicas especialmente de la industria de la comunicación y de la información. A nivel de las formas de empresa, las multinacionales y las empresas red se encuen- 
tran cada vez en mejor condición, por el desarrollo técnico, de elevarse en su actividad económica por encima de las fronteras nacionales.

- Cambios en el mapa geoeconómico y geopolítico en cuanto al reparto del excedente a nivel mundial, preeminencias, alianzas, tipos y bloques de naciones.

* Una tendencia hacia la integración inter-nacional no sólo por la anterior causa, sino por el surgimiento de bloques de estados unidos que permiten un mayor espacio de desenvolvimiento de las empresas para hacerlas más competitivas a nivel mundial.

Los ejemplos más sobresalientes son hasta ahora en los países dominantes a nivel internacional. Por un lado el objetivo de los países europeos de una sola frontera, el movimiento libre de capitales y personas a su interior y la unidad monetaria propuesta para 1992. Por otro lado, el proyecto de integración económica entre los EEUU y Cánada.

- La distención ${ }^{3}$ en la polaridad de los dos grandes bloques económicos y la integración de los países socialistas al nuevo mercado mundial. La apertura de China al comercio internacional y la progresiva resolución de las contradiciones Chino-Soviéticas. Una profundización de la mundialización de las relaciones de producción superior a las de períodos anteriores, tanto en cuanto a transnacionalización de capital como en los movimentos reinvidicativos.

Estas tendencias hasta ahora son nada más que indicios del nuevo orden internacional en posibilidad de surgir y en ningún momento son caracteristicas definitivas y definidas. Estan por lo tanto, lejos de constituirse en el espacio económico acorde o necesario a las nuevas demandas del capital como totalidad mundial. Es la no consolidación de éstas relaciones lo que abre la posibilidad de estancamiento económico de crisis recurrentes o más profundas del sistema económico. Es necesario enfatizar que este nuevo orden es nada mas una alternativa ante las crisis más profundas que en el futuro inmediato tienen similares posibilidades de concretarse.

La nueva estructura no es algo predeterminado o prediseñado, será el producto de la confluencia y contradicciones entre las diferentes fuerzas a nivel mundial. Es una contiguración que contendrá una nueva estructura hegemónica producto de un nuevo y dinámico equilibrio de fuerzas. La contradicción dinámica de las diferentes fuerzas, se plantea en diferentes planos y niveles de la realidad: clases, partidos, naciones, ramas, empresas, internacionales (socialcristianas, socialdemócratas, 
comunistas, de derecha etc).

Por otro lado, éstos cambios no sólo se reducen a la estructura técnica y económica de la sociedad sino que implicarán, al igual que en períodos anteriores, grandes transformaciones en la superestructura social. Conllevan cambios en las formas de gobierno, desarrollo de nuevas formas jurídicas, transformación de los valores y de ideologías, desarrollo de las ciencias sociales y naturales, surgimiento de nuevas escuelas teóricas o el resurgimiento, transformado, de las anteriores (el reaparecimiento modernizado de los neoclásicos y la crisis del Keynesianismo es un ejemplo de ello). Pugnas ideológicas que se sustentaban en la particularidad historica de la relación del anterior período y que lo caracterizaban, quedarán en el pasado y darán surgimiento a nuevas disputas. Es posible preveer la transformación del sistema de las NNUU, el surgimiento de un estado multinación integrado por las principales potencias que coordine o determine la política económica a nivel internacional.

Las actuales reuniones periódicas de los jefes de estado de las potencias industrializadas (y la solicitud de la Unión Soviética para integrarse a éstas reuniones cumbres) son posiblemente indicios para la conformación de un nuevo tipo de estado inexistente aún que sustituya el'papel rector, normativo, cohercitivo en parte de las NNUU y en parte de los EE.UU que hasta ahora han venido desempeñando y se encuentran en un franco desequilibrio.

En el surgimiento de éstos nuevos fenómenos el peligro para los analistas estriba en tratar de conceptualizar hacia el futuro con categorias basadas en las formas de estados precedentes. Ver la estructura futura como un reordenamiento demostraria la inflexibilidad teórica de conceptualizarlo, talvez esto se encuentre presente, por ejemplo, en las hipótesis planteadas por Gunder Frank y retomadas por Samir Amin sobre los escenarios futuros: "Primera Hipótesis: el estallido de la CEE y la encarnizada lucha de los estrechos nacionalismos. Segunda Hipótesis: el reagrupamiento atlantista y la confrontación Este-Oeste. Tercera Hipótesis: el cambio de rumbo y el acercamiento de las dos Europas." .(Samir Amin: Otra Configuración de las Relaciones Oeste-EsteSur. Es deseable, probable o posible? Cuadernos de Trabajo de HEGOA, N²0, Junio 1989 pág 13).

La diversidad implicita en estos cambios ya no son una novedad, ni en Europa ni en América Latina, más aún hay organismos Europeos especializados (Grupo de Roma, PROMETHE, ESPRIT, RACE, EURE$K A$, etc.) en estudiar y prever las múltiples implicaciones a fin de diseñar políticas que permitan un desarrollo y transición adecuada que eviten 
inadaptaciones o remoras socioculturales y técnicas hacia esos cambios.

En el reciente seminario en homenaje al Dr. Raul Prebisch, realizado por el INTAL y la CEPAL uno de los conferenciantes invitados afirmaba:

"Estos son, sin embargo, los aspectos obvios y fáciles del cambio. La optimización de los procesos productivos y la presentación de nuevos productos son, de cierta manera, la punta de un lceberg. También se modifican la naturaleza de la actividad económica y la forma en que nos relacionamos con los bienes materiales y con las demás personas. Una parte de estas modificaciones de carácter más profundo tiene como causa directa el cambio tecnológico; en muchas otras, la tecnología tiene una función catalizadora. Pero también nuestros valores, los cambios en las expectativas respecto de nosotros mismos y de las demás personas y las otras naciones, desempeña un papel central en el proceso de cambio que se opera en la economía."

"El intento de resumir en una sola fórmula un patrón tan diverso y de tanto alcance no puede sino conducir a la simplificación. No obstante, puede decirse que el papel desempeñado por la información en todos los ámbitos de la economía y de la sociedad ofrecen un angulo inmejorable para mirar de forma más lúcida posible el proceso en su conjunto" (INTAL CEPAL. América Latina en la Economia Mundial, pág 121-122, Santiago de Chile, 1988).

\section{Perspectiva para EI Salvador y los países de América Latina}

En una entrevista concedida por Samir Amin en la publicación número 2 de la revista Informa (Julio de 1985), desde la perspectiva Africana, éste hacia los siguientes comentarios:

"Esa época ya terminó y creo que nunca volveremos a la misma situación. Pienso que ante ésta crisis hay dos actitudes posibles: la primera es la que se deduce del término que usted acaba de emplear, adaptarse, es decir tratar de encontrar un nuevo lugar en el nuevo sistema que va a instaurarse y que todavía no se ha cristalizado y del que no se conocen aun los pormenores; la segunda consiste, por el contrario, en guardar cierta distancia respecto a este sistema desconocido. Temo que para la mayoría de los paises del tercer mundo y probablemente para casi la totalidad de los paises Arabes y Africanos, ajustarse al nuevo sistema que se está definiendo no sea una tarea verdaderamente posible y que sólo le ofrezca posiciones subalternas."

"La actitud a corto plazo podría ser muy pesimista, ya que efectivamente se observan tres cosas: La lógica de la expansión capitalista que en cuanto a Africa se refiere, la margina y la destruye, la lógica de la 
exterminación y la lógica del instrumento utilizado para justificar el aumento del racismo en Europa."

Ciertamente la orientación de estos cambios no son favorables para los países del tercer mundo, como los de América Latina y más específicamente para los países más débiles o subdesarrollados económicamente como El Salvador más aun, si tomamos en consideración que la tendencia para el conjunto de Latinoamérica ha sido declinante en cuanto a importancia económica dentro de la economía mundial.

Para la Comunidad Económica Europea, América Latina disminuyó su importancia entre 1980 y 1986 tanto como región vendedora como compradora. Como proveedora a la CEE bajo su ponderación de 2.9 a $2.6 \%$ del total de importaciones Europeas, como compradora pasó del 2.6 al $1.7 \%$ del total de exportaciones Europeas.

Desde la perspectiva de EEUU también ha disminuido su importancia, las importaciones estadounidenses desde A.L. pasaron de representar el $16 \%$ al $14 \%$ entre 1981 a 1985 .

Desde la perspectiva latinoamericana se ha incrementado la dependencia comercial con los EEUU entre finales de la década del 70 y mediados de la 80 . El peso de las exportaciones hacia norteamérica pasaron del $35 \%$ al $50 \%$ del total de exportaciones latinoamericanas. Mientras que del lado de las importaciones latinoamericanas, EEUU paso de proveer del $30 \%$ al $40 \%$ del total de importaciones latinoamericanas.

Esta misma disminución en importancia se observa en las relaciones con el Japón y el CAME. También ha disminuido el comercio intraregional de América Latina.

América Latina sólo ha visto incrementada su importancia como región deudora en el sistema financiero internacional. Con ciertas excepciones pero visto en su conjunto, el saldo relativo con respecto a otros países en cuanto importancia económica ha sido desfavorable para LA, teniendo una desmejoria en la escala de las naciones a nivel global en los últimos años.

De continuar esta tendencia, nuestros paises tendrán una posición cada vez más desfavorable para adaptarse a los cambios y en consecuencia una posición más desventajosa y subordinada a las economías centrales. No es posible engañarse en cuanto a la orientación de éstos cambios en el sentido que fortalecen el núcleo dominante de los paises industrializados y deterioran los términos de intercambio con las naciones productoras de productos primarios y materia primas. 
Los cambios en la composición técnica al interior del capital social son orientados en un futuro inmediato a subordinar más el trabajo al capital y a elevar a éste con mayor independencia sobre aquel; a subordinar las ramas $e$ industrias periféricas a las de vanguardia; a deteriorar los términos de intercambio y por lo tanto a una mayor transferencia de excedente de las ramas con menor densidad de capital a las de mayor composición técnica; a una mayor desintegración periférica en función de una mayor integración central.

Los cambios tecnológicos en este sentido desmejorarán aun más las relaciones económicas entre América Latina y el mundo industrializado de continuar la articulación por medio de ramas de industrias primarias, agroexportadoras y extractivas.

Por ejemplo, el actual desarrollo de la biotécnica en Europa en el caso de las hormonas para acelerar y mejorar el crecimiento de ganado vacuno pone en gran desventaja la exportación de carne hacia Europa. Lo mismo pasa con los diferentes alimentos a los cuales son aplicables tales tecnologías asi como con materias primas minerales como el caso de la quimiotécnica y el desarrollo de nuevos materiales.

En cuanto a la tendencia hacia la integración más profunda con el mercado internacional, es claro que nuestros paises latinoamericanos no podrán escapar a este proceso. Los resultados en los años recientes, si nos atenemos a los indicadores económicos, son precisamente a una integración en una posición más subordinada y simultáneamente a una mayor desintegración como región.

Este panorama es aún mas desfavorable para el caso salvadoreño dado su espacio económico y el tipo de productos con los que se inserta en el mercado mundial. Proceso que se ha visto reforzado por la guerra y el estancamiento de la estructura productiva. Por ejemplo, en los Informes del Desarrollo Mundial publicados por el Banco Mundial, El Salvador ha visto decaer su posición entre las naciones, de la posición 54 en el informe de 1980, a la posicion 47 en el informe de 1985.

De adoptar una posición pasiva o aislacionista ante estas tendencias - simplemente ignorarlas, este panorama sombrio se ira concretando para America Latina ya que como se ha observado en anteriores períodos, las tendencias económicas mundiales tarde o temprano terminan por imponerse. El desafio en este sentido no esta en luchar contra las tendencias, o de ser un simple espectador condicionado, sino en saber precisar e identificar aún mas las líneas de desarrollo para adecuarse lo más pronto a ellas y orientar el desarrollo económico en función de lograr una integración adecuada a nuestros intereses. No es navegar 
contra viento o marea sino canalizarla en función de aprovechar tal fuerza como propulsión a los objetivos particulares de la región. Esto lo está haciendo Europa y también la Unión Soviética por citar algunos ejemplos. Entonces la pregunta es por qué no América Latina o El Salvador en particular. Claramente las posibilidades nuestras son más limitadas pero esto no implica adoptar una política pasiva o de incapacidad.

En la conciencia de los grandes desafíos y en la disyuntiva para América Latina en el nuevo período se ha avanzado en los últimos ańos. También en la perspectiva de la actitud ante cambios, falta aun traducir de forma concreta tal conciencia con medidas de carácter práctico y regional. La integración a nivel subregional o regional, no se plantea como sueño romántico sino como una necesidad política y económica para América Latina y El Salvador.

\section{Desafios y tareas para EI Salvador}

Las tareas y desafios para nuestro país se derivan del contraste de las tendencias mundiales contra la actual situación politica y económica de El Salvador.

\section{1' Idea:}

El desarrollo de la nueva base técnica implicará una mayor integración económica mundial del cual no se podrá substraer ningún país. El espacio de desenvolvimiento de las fuerzas productivas será hoy más que nunca, el ámbito internacional.

Estos fenómenos implicarán una mayor internacionalización de los procesos productivos y más específicamente de la fuerza de trabajo en su desplazamiento geográfico y en su movimiento reinvindicativo. Por otro lado se entrará en un proceso en que las fronteras nacionales serán aun más diluidas y difusas ante los procesos económicos de producción, intercambio y distribución. El proceso de mayor integración al mercado internacional tiene que ser mediado por una integración en bloque a través de la subregión (CA) o de la región(LA).

\section{2! idea:}

Las economias nacionales de pequeñas magnitudes tendrán menos posibilidades de concentrar esfuerzos productivos para enfrentar dichos desatios, pero a la vez les podria permitir una mayor flexibilidad de maniobra para adaptarse a ciertos cambios y desarrollar nuevas ramas, por no tener comprometidos recursos económicos en ramas con bases técnicas del periodo anterior. 
En el proceso de profundización de la integración se abrirán oportunidades de diversificación en las relaciones económicas con diferentes áreas y países. Para el caso salvadoreño se presentan oportunidades de singular importancia con la Comunidad Económica Europea. Es necesario desarrollar en las diferentes clases (burguesia, obreros, etc.) una conciencia práctica en las relaciones comerciales tanto con el Este como con el Oeste. Al respecto se puede citar la política comercial pragmática de la Unión Soviética y China.

\section{4' Idea:}

En este nuevo período se debe de tener claro que aunque coyunturalmente los precios relativos de los bienes primarios, agropecuarios y materias primas como bienes de exportación sufran una mejoria relativa, la tendencia secular de tales productos es al deterioro. Centrar una estrategia de integración y desarrollo en tales productos, por nuevos o diversiticados que sean, conducirá tarde o temprano a una condición desventajosa en los términos de intercambio. Dada la transnacionalización de los procesos productivos el volumen relativo de las relaciones comerciales mundiales se incrementará significativamente con respecto al anterior período. El desarrollo de las exportaciones será en consecuencia una realidad y una necesidad. En tal sentido el fomento indiscriminado de las exportaciones por las exportaciones más que constituirse en una política de orientación económica significará someterse de forma ciega a las tendencias del mercado, que conduciría a nuestro país a una posición más débil. Es una forma de política inercial, o la ausencia de política de exportaciones. Tienen que identificarse y concentrarse esfuerzos en pocas ramas que ofrezcan beneficios estratégicos más que inmediatos. Las exportaciones de bienes primarios con poco valor agregado debe desincentivarse e irse trasformando por procesos agroindustriales en la exportación de productos con un segundo o tercer nivel de transformación a fin que conlleven un mayor nivel de valor agregado.

\section{5' Idea:}

Las experiencias positivas de otros países en la integración al mercado mundial, o lo contrario en su desvinculación de forma ventajosa en el anterior periodo, se deben ubicar, como una experiencia irrepetible dado que se han desarrollado en un contexto diferente al que actualmente se esta configurando. Esto implica que tanto las experiencias capitalista como las socialistas, son irrepetibles, y esas mismas eco- 
nomías se verán o se encuentran actualmente en la necesidad de un proceso de adaptación ante la forma gigantesca del proceso integrativo.

\section{6" idea:}

Las nuevas técnicas en los procesos productivos en las ramas de vanguardia para su importación deben enfrentar los menores obstáculos, ya que más temprano que tarde penetrarán en la economía nacional. $Y$ entre más temprano esto sea, será posible iniciar un proceso de aprendizaje práctico a nivel tecnológico y sus potencialidades para ser ocupadas en la integración en los procesos de producción y las exportaciones. El retraso de la penetración y ampliación en el uso de computadoras en las diferentes actividades económicas, es un ejemplo de como la actual generación de intelectuales que ejercen el poder de decisión en los diferentes ámbitos sociales y económicos se convierten actualmente en un serio obstáculo ante una necesidad que a estas alturas se ha convertido en básica de los procesos administrativos. Es lastimoso ver a gerentes de grandes empresas, directores de instituciones particulares o rectores de universidades que obstaculizan la innovación en los procesos administrativos dado su limitado horizonte y capacitación técnica en éstos aspectos. Aquí se aplica el proverbio, la cabeza retrasa a todo el cuerpo.

\section{7' idea:}

Para el caso Salvadoreño, el desarrollo de empresas redes se puede convertir en una particular alternativa de desarrollo eficiente ante demandas del mercado interno como del mercado mundial. Lo pequeño cualificado y articulado puede revelarse en ciertas áreas e industrias como superior en eficiencia, esto es válido tanto para la producción de bienes materiales como en la prestación de servicios sociales y a las empresas.

\section{8' idea:}

Es necesario una profunda reforma educativa en función de estos cambios técnicos, económicos y sociales, acorde a un plan nacional de desarrollo dentro del nuevo modelo de reproducción a escala mundial. En esta la educación de adultos debe tener una mayor relevancia de la que ha tenido hasta ahora, y ser vista como inversión (rentabilidad social inmediata).

La reforma educativa no debe de limitarse al aula, y tiene que ser vista como transformación de la conciencia tecnocientífica de la sociedad para adecuarse a los cambios. 


\section{Idea:}

El momento de reinserción en el nuevo sistema económico mundial no es neutro y determina en gran medida la posición estructural que se ocupará en las relaciones económicas. En este punto es de mucha importancia identificar la actual crisis mundial como fase de transición y por lo tanto de oportunidad, ya que en este período las relaciones no están claramente estructuradas y es posible ganar posiciones y ventajas en las relaciones. Este período de transición es limitado, posiblemente hasta el segundo quinquenio de la década de los noventa. Una vez llegado a este momento las naciones resagadas ocuparán papeles en una posición de subordinación aun más desfavorable. Las tendencias del capital mundial no esperarán a que El Salvador resuelva sus conflictos.

\section{0" Idea:}

Lo más importante para nuestro caso particular.

a. Las políticas de ajuste económicas aunque pueden ser necesarias, no dejan de ser eso, políticas de ajustes, y no son políticas de readecuación del sistema económico ante los nuevos desafíos, esto por muy políticas de ajuste estructural que se llamen.

b. Independientemente de la resolución del conflicto salvadoreño las orientaciones unilaterales en extremo han demostrado su limitación. Dada la correlación de fuerzas será necesario un consenso mínimo que tome en cuenta los intereses de las diferentes fuerzas sociales en función de esfuerzos convergentes en aras de los intereses globales.

Por otro lado, la instauración del socialismo, por ejemplo, no es un problema de voluntad política o de acierto en la conducción, son en primera instancia un problema objetivo del desarrollo de las fuerzas productivas y de su inserción en la estructura productiva a nivel mundial, fuerzas productivas que tal como se afirmó anteriormente no ubican su espacio de desarrollo en el ámbito de las naciones sino de la estructura mundial. Es claro que en el nuevo periodo presenciaremos el surgimiento de nuevas formas del socialismo diferentes sustancialmente a las del pasado, ésto es válido tanto para los actuales paises socialistas como para aquellos en donde existen fuerzas que se encuentran en lucha por tal sistema o en fase de transición.

c. El consenso en esta perspectiva debe de entenderse no solo como consenso político, sino también como consenso económico que afecta la distribución del producto generado entre los diferentes 
grupos sociales y la conducción del proceso productivo nacional.

e. La conformación de este consenso es un requisito para enfrentar los desafios para el país ante el nuevo período, y una razón de peso para la búsqueda lo más pronto posible de la resolución de la guerra.

Es cierto que la dictadura tanto de una forma como de otra, es una alternativa en la búsqueda y conducción centralizada hacia una nueva inserción, pero dada la relación de fuerzas no es posible en el futuro inmediato y los desatios económicos para EI Salvador requieren respuestas entre más inmediatas mejor.

f. Se debe de desarrollar una amplia discusión, toma de conciencia y comprensión sobre los procesos mundiales en marcha y las diferentes ramificaciones de los desafíos para la sociedad salvadorena y los diferentes grupos sociales. Sobre éstos cambios pueden existir diferentes interpertaciones así como diferentes marcos metodológicos, pero en lo que existe consenso y debe haberlo también en El Salvador, es que realmente se están dando.

\section{Epilogo}

Es necesario saber distinguir entre lo que deseamos que ocurra tanto en El Salvador como en la economía mundial, de lo que probablemente ocurrirá, como también de lo que posiblemente pueda pasar. El problema, sin embargo, en las Ciencias Sociales es que lo que vemos como probable esta fuertemente influenciado por lo deseable, no existe la objetividad en abstracto. En esta perspectiva es necesario retomar y explicitar al final de este breve ensayo ciertas proposiciones y elementos metodológicos, a manera de epílogo.

\section{a. La crisis internacional y sus salidas.}

La crisis internacional actual es un momento del desarrollo del capital a nivel mundial aun no superada, su duración en el tiempo no es algo que se pueda definir con precisión. La salida dependerá de la capacidad de contigurar una nueva estructura de relaciones económicas a nivel mundial que cree a la vez, el espacio económico necesario para la aplicación y desarrollo potencial de los grandes cambios tecnológicos de los últimos años, superando el actual espacio económico y la polarización entre las diferentes fuerzas sociales en el escenario mundial.

\section{b. La nueva configuración como producto de las fuerzas interac- tuantes.}

Los cambios tecnológicos sientan la base para esta nueva con- 
figuración de relaciones, sin embargo la especificidad de la estructura es un producto que se articula como resultado de las relaciones de fuerzas entre los diferentes agentes involucrados. Dependiendo del nivel de análisis, estos grupos pueden identificarse como grupos, clases sociales, naciones, bloques de naciones. Las nuevas relaciones "este-oeste", "norte-sur" serán producto de la acción y reacción de estas fuerzas en la coyuntura mundial. En este sentido los cambios cualitativos en la composición orgánica del capital representan los cambios también cualitativos en las relaciones de producción, entre trabajo pretérito y trabajo vivo o en su personificación como grupos sociales.

\section{c. Las categorias del pasado y el nuevo orden.}

No hay que ver desde atras o conceptualizar el futuro con categorias del pasado. Si bien es cierto que la nueva configuración mundial tiene como antecedente al período de la segunda postguerra es errado buscar un orden en el cual solo cambie la preeminencia de naciones. La pregunta por ejemplo de quién sustituirá a los EEUU lleva implícita la concepción de un simple reordenamiento de hegemonia, cuando el mismo significado y dimensión del estado-nación a nivel internacional se verá modificado. Es necesario enfatizar que las relaciones inter-naciones (internacional), son un segundo nivel de la realidad, determinado por la articulación de la estructura productiva a nivel mundial.

Por ejemplo la existencia de las naciones africanas y asiáticas o lo que se entiende actualmente por Inglaterra o Francia como estados, era dificil de concebir en el anterior periodo, a principios del presente siglo. Si comparamos los dramáticos cambios en el orden internacional entre los dos últimos períodos podemos imaginarnos lo distinto que podría ser ese nuevo orden inter-naciones.

\section{d. Mundialización y bloques.}

En la conformación de una teoría sobre el desarrollo de la economia mundial como totalidad ${ }^{4}$ es necesario evitar los siguientes errores:

- Una visión dualista y plana del desarrollo reducida a dos dimensiones, en la cual los cambios socioeconómicos en el bloque capitalista o socialista solo se vean, en cuanto a sistema, como alejamiento o aproximación de un punto a otro. Esta reducción en el análisis implica a la vez concebir la economia mundial como dos mundos separados, dual.

-El otro extremo, en voga en muchos analistas europeos, es precisamente lo contrario, al reducir la diferencia o la especificidad en la lógica del desarrollo de los bloques, a una sola. 
Existe un consenso sobre las potencialidades de los nuevos cambios hacia una mayor integración y mundialización económica. En el análisis de los acontecimientos mundiales el reto estriba en conformar una nueva teoria totalizadora del desarrollo que implica una explicación unitaria de la dinámica de conjunto y que a la vez contenga la diferencia de los procesos particulares a cada bloque. En esto se aplica la categoria de totalidad como Unidad de la Unidad y la Diferencia.

\section{e. Desarrollo naclonal y marco Internacional.}

Lo anterior se aplica, pero de diferente forma, también para el análisis del desarrollo de paises. No se puede explicar en profundidad la lógica del desarrollo mundial por medio de un marco del desarrollo de las naciones, la historia de la economía mundial no es el conjunto del desarrollo de las naciones y viceversa, aunque solo sea porque el significado del fenómeno "nación" cambia de un periodo a otro, aunque éstas estén situadas en el mismo espacio geográfico y lleven el mismo nombre. A la vez no se puede conformar una teoría del desarrollo reduciéndola a la historia económica de las naciones y viendo una con respecto a otra como realidades externas.

Las posibilidades y dirección del desarrollo de un país se dan dentro de un marco y a la vez son parte del desarrollo mundial.

\section{f. En el caso salvadorefio.}

La actual crisis, la guerra, en nuestro país es parte del proceso de definición del nuevo orden mundial, así como la salida a la actual crisis nacional esta determinada por la manera en que se configure la estructura económica mundial. En este punto es necesario para las fuerzas políticas diferenciar entre lo utópico, lo pragmático y lo práctico así como entre el sistema que se desea y propugna, el que probablemente surgirá y el posible de construir acorde a las fuerzas de los contendientes.

La nueva conformación nacional que surja estará en mejores condiciones dentro del panorama mundial en proporción y dependencia de la prontitud, asi como de la profundidad en que dentro de la actual crisis se resuelvan y superen los limites que estuvieron en la base de ella.

No hay duda que las teorias sobre el desarrollo, la economia mundial y la historia económica nacional están en crisis y esto nada mas significa que se está desarrollando en sus cimientos, porque crisis significa eso, disolución de lo viejo y conformación de lo nuevo y de esto no se substrae la teoria económica en sus mas diferentes tendencias ideo- 
lógicas. Mal hariamos en aferrarnos a categorias del pasado pero también mal se haria al no retomar, transformandolas, experiencias anteriores. Al demumbarse un período con el también caen sus contradiciones especificas. Los grandes debates teóricos entre escuelas, por ejemplo entre Keynesianos y Marshalianos o Neoclásicos, entre Stalinistas y Troskistas (solo para poner ejemplos extremos), pierden su base de discusión desapareciendo o se retransforman sobre un nuevo escenario.

Los puntos aqui planteados son un ensayo sobre un problema de actualidad que por las condiciones internas del país, se le ha dedicado poca atención por parte de las fuerzas sociales salvadorenas, pero que sobre el cual, más temprano que tarde, se tendrán que redefinir posturas, conceptos y estrategias.

\section{Notas}

1. Cosa curiosa, todos estos marcos teóricos y metodológicos que implican a la vez tendencias ideológicas, también han entrado en crisis. Se habla de crisis de las Ciencias Sociales (Economía, Sociología, etc.) precisamente porque constituyen parte de la conciencia social. Esto necesariamente es así porque es a través de las crisis como se desarrollan tanto la realidad objetiva como su manifestación en la ciencia, la religión y el arte. Es precisamente dentro de ellas que han surgido y desarrollado las grandes escuelas teóricas artísticas y religiosas así como también el estilo de vida.

2. Básicas según la estructura técnica del capital social.

3. Esta integración debe de entenderse de forma suigeneris. Al integrarse estos países están con esa mismo acción conformando un mercado diferente al actual (básicamente dividido). A la vez esta integración posiblemente tendrá una naturaleza o forma diferente a la de los "países occidentales y del tercer mundo".

4. Las teorización de la economía como unidad global, de forma sistemátic a y como objeto de teorización, realmente es un producto de los últimos años.

\section{Bibliografla}

Banco Mundial: Informe sobre el Desarrollo Mundial 1979, 1980, 1981, 1982, 1983, 1984, 1985, 1986, 1987.

CEPAL: Hacia un desarrollo sostenido en América Latina y el Caribe: restricciones y Requisitos. Cuaderno de la CEPAL \# 61. Enero, 1989.

CEPAL: La Evolución de la Economia en América Latina en 1987. Cuaderno de la CEPAL \# 62. Marzo, 1989.

CEPAL: Revista de la CEPAL \# 37. Abril, 1989.

INTAL Y CEPAL: América Latina en la Economia Mundial. Seminario en homenaje al Dr. Raúl Prebisch.(Compilación de Exposiciones) Santiago de Chile 1988.

Madison Angus. Las Fases del Desarrollo Capitalista. Una Historia Económica 
Cuantitativa. El colegio de México/ Fondo de Cultura Económica, México D. C. 1986.

Amin S. Y otros: Dinámica de la Crisis Global. Siglo XXI, México,1982.

Amin S. Otra Cofiguración de las Relaciones Oeste-Este-Sur. Es deseable, probable o posible?. Cuadernos de trabajo de HEGOA, Ne 0, Bilbao, junio1989.

Digitalizado por Biblioteca "P. Florentino Idoate, S.J." Universidad Centroamericana José Simeón Cañas 